\title{
Use of Air Displacement Plethysmography in the Determination of Percentage of Fat Mass in African American Children
}

\author{
ANDREA C. BUCHHOLZ, KAREN M. MAJCHRZAK, KONG Y. CHEN, \\ SADHNA M. SHANKAR, AND MACIEJ S. BUCHOWSKI
}

\begin{abstract}
Department of Medicine, Division of Gastroenterology, Hepatology and Nutrition [A.C.B., M.S.B., K.M.M., K.Y.C.], Vanderbilt University Medical Center, Nashville, TN 37232-2279, U.S.A.; Division of

Pediatric Hematology/Oncology [S.S.S.] Vanderbilt University School of Medicine, Nashville, TN 37232-6310, U.S.A.; and Meharry Medical College, Center for Nutrition [A.C.B., M.S.B.], Nashville, TN 37208 , U.S.A.
\end{abstract}

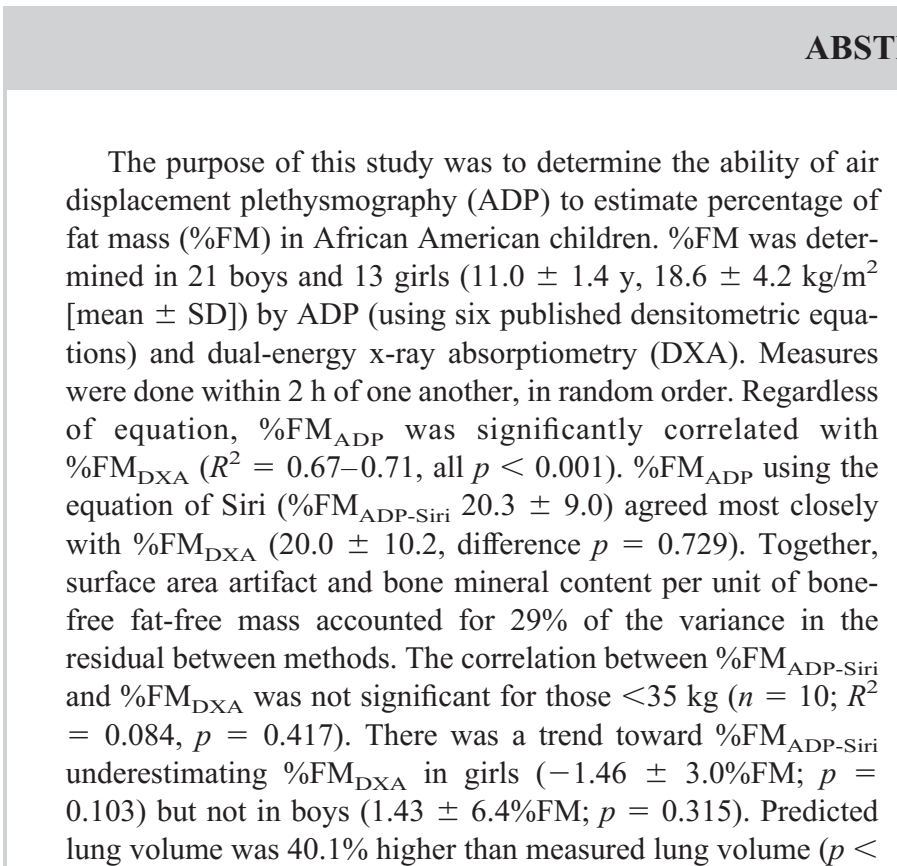

Accurate assessment of body composition is a key component of research on childhood obesity and the effects of disease processes on pediatric health. Many methods for measuring body composition in children exist, each with its inherent strengths and weaknesses. Multicompartment models, combining body density, total body water, and total body mineral, are

Received September 19, 2003; accepted February 6, 2004.

Correspondence: Maciej S. Buchowski, Ph.D., Center for Nutrition, Department of Family and Community Medicine, Meharry Medical College, Nashville, TN 37208, U.S.A.; e-mail: maciej.buchowski@vanderbilt.edu

This work was supported in part by grants from the National Institutes of Health (HBL67715 and GM008037) to M.S.B., General Clinical Research Center Grants RR00095 (to Vanderbilt University) and RR-1179204 (to Meharry Medical College), and Clinical Nutrition Research Unit Grant DK-26657 (to Vanderbilt University). A.C.B. was supported by RR-03032.

DOI: 10.1203/01.PDR.0000130477.05324.79
0.001). $\% \mathrm{FM}_{\mathrm{ADP}-\text { Siri }}$ determined using predicted lung volume was $23.5 \pm 8.9$, higher than that using measured lung volume ( $p$ $<0.001)$ and higher than $\% \mathrm{FM}_{\mathrm{DXA}}(p=0.001)$. We conclude that in 9- to 14-y-old African American children and provided lung volume is measured, \%FM using ADP with Siri's equation approximates that obtained by DXA. Body composition results determined by ADP in children $<35 \mathrm{~kg}$ should be interpreted with caution. (Pediatr Res 56: 47-54, 2004)
Abbreviations
ADP, air displacement plethysmography
BFFFM, bone-free fat-free mass
BMC, bone mineral content
BMI, body mass index
DXA, dual energy x-ray absorptiometry
\%FM, percentage of fat mass
SAA, surface area artifact
SEE, standard error of the estimate

frequently used to derive reference measures of body composition but are costly, time-consuming, and often not practical. Thus, researchers and clinicians often rely on two-compartment models that simply separate the body into fat and fat-free components.

A two-compartment method being used with increasing frequency is air displacement plethysmography (ADP). ADP is based on classic gas laws, using a pressure-volume relationship to derive body volume and therefore body density of a subject seated inside a test chamber. The physical design and operating principle of ADP have been described in detail elsewhere (1). ADP was developed into a viable system for routine use in the mid-1990s (1) and has since been validated in children against dual-energy x-ray absorptiometry (DXA), hydrodensitometry, and the standard reference four-compartment model with vari- 
able success (2-6). Many equations may be used to convert body density to percentage of fat mass $(\% \mathrm{FM})(7-12)$; this may be one reason for the discrepant findings across studies. No study using ADP has reported prospectively testing these equations against a reference method in African American children. The issue of age and ethnicity is not trivial, as changes in body composition associated with growth may affect the applicability of certain body composition methods (13). As well, there are differences in bone mineral content (14-16), body density (8), and \%FM (17) in African American subjects versus those of other ethnic origins.

Another reason for the discrepant findings may be the determination of lung volume, which is used in ADP to correct body volume in the calculation of body density. Lung volume can be measured directly or can be predicted, most commonly with the equation of Crapo et al. (18), which was validated in adults. Lung volume has been predicted in a number of pediatric studies using ADP $(2,4,19,20)$, yet only one of these (2) determined the effect of predicted versus measured lung volume on results. The authors concluded that use of predicted lung volume was not the source of the observed bias in body density by ADP versus hydrodensitometry. However, since these studies were published, predicted lung volume was found to be higher and only modestly associated with measured lung volume in a study of children aged 8-17 y (21). As a result, \%FM by ADP was significantly greater than that using measured lung volume and greater than $\% \mathrm{FM}$ by hydrodensitometry.

The objectives of our study were 2-fold. We sought, in a group of African American children, to test $\% \mathrm{FM}$ determined by ADP using six body density equations against that determined by DXA. DXA was chosen as the reference method because it is independent of any assumptions around body density and has been validated as a reliable estimate of \%FM against the four-compartment model in human subjects $(10,22)$. We also sought to compare the use of predicted versus measured lung volume in the determination of \%FM by ADP.

\section{METHODS}

\section{Subjects}

Subjects for the current study represented a subsample from a larger, longitudinal study on the effects of sickle cell disease on energy metabolism and body composition. We recruited 34 African American children (21 boys, 13 girls) from Nashville and Memphis areas, TN, U.S.A., through brochures distributed in local communities. Ethnicity was determined by parental self-report. Sixteen children had sickle cell disease and were recruited through brochures and from sickle cell clinics in Nashville and Memphis. Subjects with sickle cell disease were in steady state and had not had a crisis or hospital admission in the $14 \mathrm{~d}$ before study enrollment. All subjects underwent a physical examination and medical history, administered by a physician (S.M.S.) or a registered nurse, and all were determined to be in good health. The study was approved by the Institutional Review Boards of Vanderbilt University Medical Center and Meharry Medical College in Nashville. Each child provided written assent and a parent or legal guardian provided written consent before study participation.

\section{Body Composition}

ADP and DXA measurements were performed on the same day, within $2 \mathrm{~h}$ of one another, in random order. Weight was measured to the nearest $0.1 \mathrm{~kg}$ using the BOD POD (see below) scale. This scale was calibrated regularly against standardized $20-\mathrm{kg}$ weights and was consistently within $<0.1 \%$. Height was measured to the nearest $0.5 \mathrm{~cm}$ using the stadiometer on a beam balance scale.

\section{ADP}

Body density was assessed using the BOD POD air displacement body composition system (software version 1.69; Life Measurement Instruments, Concord, CA, U.S.A.), according to the manufacturer's directions and procedures previously described (1). The instrument underwent a two-point calibration, once with the test chamber empty and once with a cylinder of known volume $(49.896 \mathrm{~L})$. Raw body volume was measured with subjects wearing minimal clothing (underpants or a tightfitting bathing suit, and no jewelry) and a bathing cap, while sitting quietly and breathing normally in the test chamber. Raw body volume was measured twice, and the mean was used to determine body density, as described below. When the two determinations differed by $>150 \mathrm{~mL}$, a third determination was made, and the mean of the two closest was used. Two investigators (M.S.B. or K.M.M.) performed all measurements.

The final step involved measurement of lung volume (thoracic gas volume), during which the subject sat quietly in the test chamber, nose clipped, while breathing through a disposable tube and filter connected to the reference chamber in the rear of the instrument. After four or five normal breaths, the subject's airway was occluded during midexhalation and the subject was instructed to make three quick, light pants. Tidal breathing was determined on the basis of the change in volume detected by the pressure transducers during normal breathing. Lung volume was then calculated on the basis of changes in pressure in the lungs detected by a transducer in the breathing circuit during airway occlusion, as follows: lung volume $(\mathrm{L})=$ functional residual capacity $(\mathrm{L})+(0.5 *$ tidal volume, $\mathrm{L})$.

Lung volume was measured for all subjects, and all achieved a figure of merit of $<1.0$. Lung volume was also predicted using the proprietary equation in the manufacturer software [a modification of the equation of Crapo et al. (18) developed in adults] as well as the pediatric equations of Rosenthal et al. (23) for functional residual capacity and Zapletal et al. (24) for tidal volume.

Body density was then determined by the manufacturer's software as follows:

BSA $\left(\mathrm{cm}^{2}\right)=71.84\left[\right.$ weight $\left.(\mathrm{kg})^{0.425}\right]\left[\right.$ height $\left.(\mathrm{cm})^{0.725}\right]$

SAA $(\mathrm{L})=\mathrm{k}\left(\mathrm{L} / \mathrm{cm}^{2}\right)(\mathrm{BSA})$

Body volume $(\mathrm{L})=\mathrm{Vol}_{\text {raw }}(\mathrm{L})+0.40 \mathrm{Lung} \operatorname{vol}(\mathrm{L})-\mathrm{SAA}$

Body density $(\mathrm{kg} / \mathrm{L})=$ weight $/$ body volume

Where BSA is body surface area, SAA is surface area artifact (used to account for changes in air temperature near the surface of subject's body), $\mathrm{k}$ is a negative constant derived by the manufacturer, and $\mathrm{Vol}_{\text {raw }}$ is body volume uncorrected for lung volume. Finally, $\% \mathrm{FM}_{\mathrm{ADP}}$ was calculated from body 
density using various published equations, summarized in Table 1 . We chose to test the Siri equation (7) because it is widely used in the literature; the equations of Lohman et al. (9), Wells et al. (10), Bray et al. (11), and Westrate and Deurenberg (12) because they were devised in African American and/or white children; and the equation of Schutte et al. (8) because it was devised in African American men. The entire measurement procedure took $\sim 15 \mathrm{~min}$. Our laboratory's intra-assay coefficient of variation for $\% \mathrm{FM}$ using $\mathrm{ADP}$ in adult men and women is $3.6 \pm 2.6 \%$.

\section{DXA}

Body composition was also assessed using DXA (Lunar Prodigy, GE Medical Systems, Madison, WI, U.S.A.). Scans were performed with Lunar pediatric software version 6.6, in fan beam mode. The instrument was calibrated before each measurement using the manufacturer's standard calibration block of thermoplastic acrylic resin, which contained three bone-equivalent chambers filled with hydroxyapatite. Bone mineral density $\left(\mathrm{g} / \mathrm{cm}^{2}\right)$ and bone mineral content (BMC; $\mathrm{g}$ ) for each calibration scan were consistently within $1 \%$ of known values. Each subject lay quietly on the DXA table and was scanned from head to toe in 5-10 min. Subjects wore light clothing with no metal objects, no shoes and socks, and no jewelry. BMC was expressed per unit of bone-free fat-free mass (BFFFM). Determination of fat mass was based on the extrapolation of fatness from the ratio of soft tissue attenuation of the two x-ray energies in pixels not containing bone. Our laboratory's intra-assay coefficient of variation for \%FM using DXA in adult men and women is $0.79 \pm 0.49 \%$. We determined the coefficient of variation in adults only because of the ethical issue of repeated exposure of children to radiation.

Data Analysis. Data were analyzed using the Statistical Package for the Social Sciences (SPSS version 11, Chicago, IL, U.S.A.). A $p<0.05$ was considered significant. Differences between subgroups (control and sickle cell boys and girls) were determined using ANOVA and Scheffé post hoc test. Three variables were not normally distributed: body mass index (BMI), body volume, and $\% \mathrm{FM}_{\mathrm{DXA}}$, as well as their log transformations, were compared across subgroups using ANOVA as described above. The conclusions from both tests were similar and so results of untransformed data are presented.

Measured and predicted lung volumes were compared using paired $t$ tests. The residuals (manufacturer predicted lung volume - measured lung volume and Rosenthal/Zapletal predicted lung volume - measured lung volume) were compared between control and sickle cell groups by Student t-test. $\% \mathrm{FM}_{\mathrm{ADP}}$ and $\% \mathrm{FM}_{\mathrm{DXA}}$ were compared using paired $t$ tests. The $95 \%$ confidence limits of the mean differences between body composition methods were determined. The agreement between methods was explored using simple linear regression and the method of Bland-Altman (25). Sperman's correlation coefficient was used to determine the relationship between the residual (best-fitting ADP equation minus DXA) and possible explanatory variables for the whole sample and separately for boys and girls, and for subjects $<35 \mathrm{~kg}$ and $\geq 35 \mathrm{~kg}$. This weight cutoff was chosen as ADP may not be valid for subjects $<35 \mathrm{~kg}$ (A.C.B., personal communication with manufacturer). Stepwise regression was then used in an effort to improve the prediction of the outcome variable, $\% \mathrm{FM}_{\mathrm{DXA}}$, for the whole sample. The regression model was tested for multicollinearity using the variance inflation factor. Results of the above tests were confirmed on the whole sample using nonparametric statistics and/or log-transformed $\% \mathrm{FM}_{\mathrm{DXA}}$; conclusions were similar and so results of parametric tests on untransformed $\% \mathrm{FM}_{\mathrm{DXA}}$ are presented.

\section{RESULTS}

Descriptive characteristics of the sample are presented in Table 2. Girls with sickle cell disease were slightly older than control girls $(p=0.023)$, and control girls had greater bone mineral density than boys with sickle cell disease $(p=0.036)$. The remaining variables did not differ across subgroups, so subsequent analyses were performed on the sample as whole.

\section{\%FM Comparison}

Comparisons between body composition methods are shown in Table 3. $\% \mathrm{FM}_{\mathrm{ADP}}$, regardless of equation, was significantly correlated with $\% \mathrm{FM}_{\mathrm{DXA}}\left(R^{2}=0.67-0.71\right.$, all $\left.p<0.001\right)$. The best agreement was with the equation of Siri, for which 1 ) the difference with DXA was small and nonsignificant $(0.33 \pm$

Table 1. Published equations used to convert body density into \%FM

\begin{tabular}{|c|c|c|}
\hline Author(s) (reference) & Sample population & Equation \\
\hline Siri (7) & $\begin{array}{l}\text { Equation based on fat-free reference body from theoretical } \\
\text { population }\end{array}$ & (495/BD)-450 \\
\hline Lohman et al. (9) & 54 prepubescent African American and white boys and girls & $(530 / \mathrm{BD})-489$ \\
\hline Westrate and Deurenberg (12) & $\begin{array}{l}\text { Derived from data of Fomon et al. (32) on } 0 \text { - to } 10 \text {-y-old } \\
\text { boys and girls, from a variety of studies }\end{array}$ & $\begin{array}{l}\text { Boys } 2-18 \text { y old: } \\
\quad\{[(562-4.2(\text { age- }-2)] / \mathrm{BD}\}-[5.25-4.7(\text { age- }-2)] \\
\text { Girls } 2-10 \text { y old: } \\
\quad\{[(562-1.1(\text { age- }-2)] / \mathrm{BD}\}-[525-1.4(\text { age- } 2)] \\
\text { Girls } 10-18 \text { y old: } \\
\quad\{[(553-7.3(\text { age- }-10)] / \mathrm{BD}\}-[514-8.0(\text { age- } 10)] \\
\quad \text { where age is in years }\end{array}$ \\
\hline Wells et al. (10) & 30 boys and girls, $8-12$ y old, ethnicity not specified & $(527 / \mathrm{BD})-485$ \\
\hline Bray et al. (11) & 129 African American and white boys and girls, $10-12$ y old & $(446 / \mathrm{BD})-402$ \\
\hline
\end{tabular}

$\mathrm{BD}$, body density. 
Table 2. Descriptive characteristics of whole sample and by sex and group

\begin{tabular}{|c|c|c|c|c|c|c|}
\hline Variable & $\begin{array}{l}\text { Whole sample } \\
\quad(n=34)\end{array}$ & Range & \multicolumn{2}{|c|}{ Control } & \multicolumn{2}{|c|}{ Sickle cell } \\
\hline Age (y) & $11.0 \pm 1.4$ & $9.0-13.9$ & $10.8 \pm 1.2$ & $10.0 \pm 1.0^{*}$ & $11.5 \pm 1.2$ & $12.2 \pm 1.4^{*}$ \\
\hline Weight (kg) & $39.8 \pm 9.3$ & $25.3-70.4$ & $39.7 \pm 8.2$ & $43.6 \pm 12.7$ & $35.8 \pm 7.8$ & $43.0 \pm 6.6$ \\
\hline $\operatorname{BMI}\left(\mathrm{kg} / \mathrm{m}^{2}\right)$ & $18.6 \pm 4.2$ & $13.5-37.5$ & $18.4 \pm 2.7$ & $20.8 \pm 7.3$ & $17.4 \pm 3.0$ & $18.3 \pm 1.6$ \\
\hline Surface area artifact (L) & $-0.587 \pm 0.070$ & -0.750 to -0.440 & $-0.580 \pm 0.059$ & $-0.596 \pm 0.083$ & $-0.564 \pm 0.063$ & $-0.638 \pm 0.074$ \\
\hline Body density $(\mathrm{kg} / \mathrm{L})$ & $1.053 \pm 0.020$ & $0.990-1.09$ & $1.060 \pm 0.017$ & $1.046 \pm 0.029$ & $1.053 \pm 0.018$ & $1.050 \pm 0.011$ \\
\hline Body volume (L) & $37.9 \pm 9.5$ & $24.6-71.4$ & $37.5 \pm 8.1$ & $42.0 \pm 13.8$ & $34.0 \pm 7.7$ & $40.8 \pm 6.0$ \\
\hline Bone mineral density $\left(\mathrm{g} / \mathrm{cm}^{2}\right)$ & $0.972 \pm 0.076$ & $0.830-1.13$ & $0.994 \pm 0.062$ & $1.020 \pm 0.086 \dagger$ & $0.922 \pm 0.057 \dagger$ & $0.966 \pm 0.066$ \\
\hline BMC/BFFFM (kg) & $0.0539 \pm 0.0104$ & $0.0404-0.0908$ & $0.0548 \pm 0.0086$ & $0.0608 \pm 0.016$ & $0.0482 \pm 0.0053$ & $0.0537 \pm 0.0049$ \\
\hline
\end{tabular}

* Sickle cell girls were older than control girls $(p=0.023)$.

$\dagger$ Bone mineral density was higher in control girls $v s$ sickle cell boys $(p=0.036)$.

$5.5 \% \mathrm{FM} ; p=0.729), 2)$ the confidence limits around the mean difference included zero $(-1.6$ to 2.2$), 3)$ the regression coefficient of the intercept was not different from zero $(p=0.811)$ and that of the slope was not different from 1 (95\% confidence intervals of slope, 0.74 and 1.17; Fig. 1A), 4) Bland-Altman analysis (Fig. $1 B$ ) indicated no bias $\left(R^{2}=0.051, p=0.200\right)$, and 5) only nine subjects (26.5\%) differed from DXA by $\geq 5 \% \mathrm{FM}$. The poorest agreement was with the equations of Lohman et al. and Westrate and Deurenberg, both of which 1) underestimated DXA by $\geq 5.4 \% \mathrm{FM}(p<0.001), 2)$ had intercepts that differed significantly from 0 , and 3 ) resulted in $\geq 22$ subjects differing from DXA by $\geq 5 \% \mathrm{FM}$. The greatest biases were demonstrated by the equations of Schutte et al. and Bray et al., for which the Bland-Altman $R^{2}$ were $\geq 0.16(p<0.05)$. All subsequent analyses, therefore, were performed using the equation of Siri (\%FM $\mathrm{ADP}-\mathrm{Sir})$.

Sperman's correlation coefficients between the residual $\left(\% \mathrm{FM}_{\mathrm{ADP}-\mathrm{Siri}}-\% \mathrm{FM}_{\mathrm{DXA}}\right)$ and possible explanatory variables are shown in Table 4. For the sample as a whole, SAA and $\mathrm{BMC} / \mathrm{BFFFM}$ were significant, and together they explained $29 \%$ of the variance in the residual $(p=0.005)$. When all variables were entered into a stepwise linear regression, the model that provided the best fit was $\% \mathrm{FM}_{\mathrm{DXA}}=-20.6+$ $0.54\left(\% \mathrm{FM}_{\mathrm{ADP}-\text { Siri }}\right)+348(\mathrm{BMC} / \mathrm{BFFFM})+0.58$ (BMI) $\left(R^{2}=\right.$ $0.87 ; p<0.001)$. There was no significant difference between $\% \mathrm{FM}$ calculated using this new equation $(20.0 \pm 3.69)$ and $\% \mathrm{FM}_{\mathrm{DXA}}(p=0.969)$, and a Bland-Altman analysis did not indicate any bias $\left(R^{2}=0.039, p=0.262\right)$. However, the new equation did reduce the $\mathrm{SE}$ of the estimate (SEE) to $3.9 \% \mathrm{FM}$ and the number of subjects for whom \%FM differed from DXA by $\geq 5 \% \mathrm{FM}$ to five.

Effects of sex and weight category. There was a trend toward $\% \mathrm{FM}_{\mathrm{ADP}-\mathrm{Siri}}$ underestimating $\% \mathrm{FM}_{\mathrm{DXA}}$ in girls $(-1.46$ $\pm 3.0 \% \mathrm{FM} ; p=0.103)$ but not in boys $(1.43 \pm 6.4 \% \mathrm{FM} ; p=$ $0.315)$. There was a higher correlation between methods for girls $\left(R^{2}=0.97, p<0.001\right.$, $\left.\mathrm{SEE}=2.36 \% \mathrm{FM}\right)$ than for boys $\left(R^{2}=0.40, p=0.002\right.$, SEE $\left.=5.8 \% \mathrm{FM}\right)$. For girls, weight, SAA, body volume, and bone mineral density all were significantly correlated with the residual, whereas for boys, no variable was associated with the residual. There was one boy for whom the residual between methods was $22.3 \% \mathrm{FM}$. When this outlier was removed from the data set, the mean difference between methods for boys was further reduced to $0.39 \pm$

Table 3. Agreement in \%FM between ADP (using published equations) and DXA, for all subjects $(n=34)$

\begin{tabular}{|c|c|c|c|c|c|c|c|}
\hline Method & DXA & $\begin{array}{l}\text { Siri } \\
(7)\end{array}$ & $\begin{array}{l}\text { Lohman et al } \\
\text { (9) }\end{array}$ & $\begin{array}{l}\text { Schutte et al } \\
\text { (8) }\end{array}$ & $\begin{array}{l}\text { Westrate and } \\
\text { Deurenberg } \\
\text { (12) }\end{array}$ & $\begin{array}{l}\text { Wells et al } \\
\qquad(10)\end{array}$ & $\begin{array}{l}\text { Bray et al } \\
\text { (11) }\end{array}$ \\
\hline$\% \mathrm{FM}$ & $20.0 \pm 10.2$ & $20.3 \pm 9.0$ & $14.6 \pm 9.7$ & $22.8 \pm 6.9$ & $14.4 \pm 9.6$ & $15.7 \pm 8.3$ & $21.8 \pm 8.1$ \\
\hline $\begin{array}{l}\text { Mean difference with DXA } \\
\text { (95\% confidence limits) }\end{array}$ & - & $\begin{array}{c}0.33 \pm 5.5 \\
(-1.6 \text { to } 2.2)\end{array}$ & $\begin{array}{l}-5.42 \pm 5.6^{*} \\
(-7.4 \text { to }-3.5)\end{array}$ & $\begin{array}{l}2.83 \pm 5.5 \dagger \\
(0.91-4.74)\end{array}$ & $\begin{array}{c}-5.5 \pm 6.0^{*} \\
(-7.6 \text { to }-3.45)\end{array}$ & $\begin{array}{c}-4.3 \pm 5.6^{*} \\
(-6.2 \text { to }-2.3)\end{array}$ & $\begin{array}{c}1.77 \pm 5.5 \\
(-0.14 \text { to } 3.7)\end{array}$ \\
\hline$R^{2}+$ & - & 0.71 & 0.71 & 0.71 & 0.67 & 0.71 & 0.71 \\
\hline Regression coefficient of slope & - & 0.96 & 0.89 & 1.1 & 0.88 & 0.89 & 1.1 \\
\hline $\begin{array}{l}\text { Regression coefficient of } \\
\text { intercept }\end{array}$ & - & 0.57 & $7.0 \S$ & -4.7 & $7.34 \S$ & $5.9 \S$ & -3.1 \\
\hline Bland-Altman $R^{2}$ & - & 0.051 & 0.011 & $0.18 \|$ & 0.013 & 0.013 & $0.16 \|$ \\
\hline $\begin{array}{l}\text { No. of subjects for whom } \\
\text { DXA and ADP differed by } \\
\geq 5 \% \text { FM }\end{array}$ & - & 9 & 22 & 10 & 24 & 17 & 9 \\
\hline
\end{tabular}

$* p<0.001$

$\dagger p<0.01$.

$\dagger$ All $p<0.001$.

$\S p<0.001$, regression coefficient of intercept significantly different from 0.

$\| p<0.05$. 

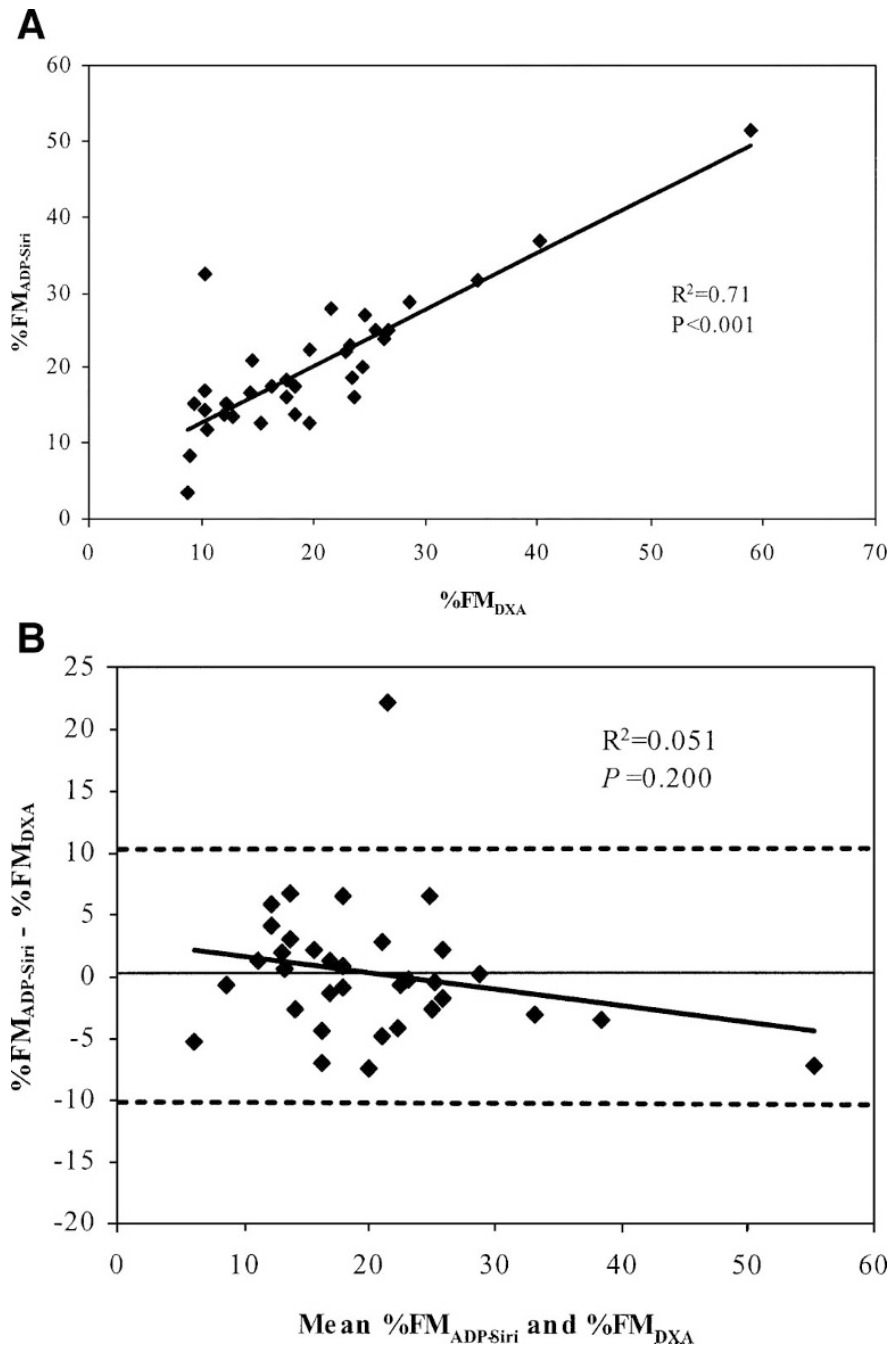

Figure 1. $(A)$ Regression plot between percent fat mass determined using dual energy $\mathrm{x}$-ray absorptiometry $\left(\% \mathrm{FM}_{\mathrm{DXA}}\right)$ and percent fat mass determined using air displacement plethysmography with the equation of Siri (7) $\left(\% \mathrm{FM}_{\mathrm{ADP}-\mathrm{Siri}}\right)$ in 34 African American children 9-14 y. (B) Bland-Altman plot between $\% \mathrm{FM}_{\mathrm{ADP}-\mathrm{Siri}}$ and $\% \mathrm{FM}_{\mathrm{DXA}}$. Solid horizontal line is mean difference between methods $(0.33 \% \mathrm{FM}, p=0.729)$ and dotted lines are $2 \mathrm{SD}$ of mean difference. Trendline in both panels is regression line.

4.4\%FM $(p=0.690)$, and the correlation increased to $R^{2}=$ $0.67(p<0.001, \mathrm{SEE}=4.3 \% \mathrm{FM})$.

There was no significant difference between methods for subjects $<35$ versus $\geq 35 \mathrm{~kg}(2.72 \pm 7.78 \% \mathrm{FM}, p=0.297$; $-0.67 \pm 4.0 \% \mathrm{FM}, p=0.420$, respectively). There was no correlation between methods for subjects $<35 \mathrm{~kg}\left(R^{2}=0.084\right.$, $p=0.417)$, and no variable explained the residual in this subgroup. Conversely, the correlation between methods for subjects $\geq 35 \mathrm{~kg}$ was high $\left(R^{2}=0.87, p<0.001\right)$; both lung volume and $\mathrm{BMC} / \mathrm{BFFFM}$ were significantly associated with the residual between methods in this subgroup.

\section{Predicted versus Measured Lung Volume}

Predicted lung volume using the manufacturer's equation was significantly higher than measured lung volume (Table 2), as was predicted lung volume $(2.24 \pm 0.30 \mathrm{~L})$ using the combined equations of Rosenthal/Zapletal (both $p<0.001$ ).
Predicted lung volume was only modestly associated with measured lung volume (manufacturer equation $R^{2}=0.34$ and Rosenthal/Zapletal equations $R^{2}=0.33$, both $p<0.001$ ). There was no difference in either residual between control subjects and subjects with sickle cell disease (manufacturer predicted lung volume - measured lung volume for controls $=$ $0.65 \pm 0.29$ and sickle cell subjects $=0.74 \pm 0.42, p=0.486$; Rosenthal/Zapletal lung volume - measured lung volume for controls $=0.48 \pm 0.31$ and subjects with sickle cell disease $=$ $0.57 \pm 0.41, p=0.431)$. When used to determine body composition, the manufacturer's predicted lung volume resulted in a group mean $\% \mathrm{FM}_{\mathrm{ADP}-\text { Siri }}$ of $23.5 \pm 8.9$, and the equations of Rosenthal/Zapletal resulted in a group mean $\% \mathrm{FM}_{\mathrm{ADP}-\mathrm{Siri}}$ of $22.8 \pm 9.0$, both higher than that using measured lung volume $(p<0.001)$ and both higher than $\% \mathrm{FM}_{\mathrm{DXA}}$ ( $p=0.001$ and $p=0.011$, respectively).

\section{DISCUSSION}

The major findings of this study are that 1 ) the validity of $\% \mathrm{FM}$ determined by ADP in this sample of African American children is in part dependent on the equation chosen to convert body density; the equation of Siri agreed most closely with $\% \mathrm{FM}_{\mathrm{DXA}}$; and 2) lung volume should be measured, not predicted, in pediatric subjects; failure to do so may result in overestimation of lung volume and therefore of \%FM.

To the best of our knowledge, ours is the first study of ADP to compare the performance of a variety of body density equations against a criterion method in African American children. For the sample as a whole, the equation with closest agreement to DXA was that of Siri (7). This was unexpected because this equation was derived from a theoretical population. Despite this, Siri's equation continues to be widely used in the literature. The reason for the poor agreement with the Schutte (8) equation is likely because the equation was validated in only 15 African American men. The reason for the poor agreement with the equations of Westrate and Deurenberg (12), Wells et al. (10), Lohman et al. (9), and Bray et al. (11) is not clear, as all were developed in pediatric populations, the last two in African American and white subjects. However, each of the above studies used different methods to derive their equations. For example, Westrate and Deurenberg derived their equation from a variety of studies that used methods such as total body water, total body potassium, and dual-photon absorptiometry. Lohman et al. used hydrostatic weighing, whereas both Wells et al. and Bray et al. used the fourcompartment model to derive their equations. Thus, differences among reference equations may be due to differences in reference methods.

Only three studies of ADP in the pediatric literature have compared the use of equations with a reference method, and all used various equations of Lohman et al. Similar to the current study, $\% \mathrm{FM}_{\mathrm{ADP}-\text { Lohman }}$ was found to underestimate $\% \mathrm{FM}_{\mathrm{DXA}}$ by $6.9 \%$ in 119 African American and white children (19). In a study of 48 children (2), there was no difference between $\% \mathrm{FM}_{\mathrm{ADP}-\mathrm{Siri}}$ and $\% \mathrm{FM}_{\mathrm{ADP}-L o h m a n}$, although agreement between $\% \mathrm{FM}_{\mathrm{ADP}-\text { Lohman }}$ and $\% \mathrm{FM}$ determined by hydrodensitometry was not reported. Fields and Goran (5) reported that 
Table 4. Sperman's correlation coefficients (r) among residuals $\left(\% F M_{A D P-S i r i}-\% F M_{D X A}\right)$ and possible explanatory variables, for all subjects and by sex and weight category

\begin{tabular}{|c|c|c|c|c|c|}
\hline Variable & All subjects $(n=34)$ & Boys $(n=21)$ & Girls $(n=13)$ & $<35 \mathrm{~kg}(n=10)$ & $\geq 35 \mathrm{~kg}(n=24)$ \\
\hline Age (y) & -0.012 & 0.237 & -0.516 & -0.091 & 0.053 \\
\hline Height $(\mathrm{cm})$ & -0.028 & 0.157 & -0.298 & 0.288 & 0.099 \\
\hline Weight (kg) & -0.26 & -0.025 & $-0.813 *$ & -0.309 & -0.098 \\
\hline BMI $\left(\mathrm{kg} / \mathrm{m}^{2}\right)$ & -0.251 & -0.192 & -0.484 & -0.503 & -0.038 \\
\hline Body density (kg/L) & -0.062 & -0.388 & 0.503 & -0.576 & 0.052 \\
\hline SAA (L) & $0.373 \dagger$ & 0.133 & $0.868^{*}$ & 0.061 & 0.326 \\
\hline Lung volume (L) & 0.158 & 0.165 & 0.038 & 0.127 & $0.422 \dagger$ \\
\hline Body volume (L) & -0.233 & 0.027 & $-0.830 *$ & -0.212 & -0.063 \\
\hline Bone mineral density $\left(\mathrm{g} / \mathrm{cm}^{2}\right)$ & -0.305 & -0.199 & $-0.599 \dagger$ & -0.564 & -0.127 \\
\hline BMC/BFFFM (kg) & $-0.508 \ddagger$ & 0.375 & -0.451 & -0.552 & $-0.476 \dagger$ \\
\hline
\end{tabular}

$* p \leq 0.001$.

$\dagger p<0.05$.

$\ddagger p<0.01$.

ADP using the equation of Lohman was a valid technique for evaluating body composition in their study of 25 African American and white children $(11.4 \pm 1.4 \mathrm{y})$, relative to the four-compartment model.

Despite the good agreement between $\% \mathrm{FM}_{\mathrm{ADP}-\mathrm{Siri}}$ and $\% \mathrm{FM}_{\mathrm{DXA}}$ in the current study, the difference between methods was $>5 \% \mathrm{FM}$ in nine subjects, suggesting that the methods may not be interchangeable at the individual level. We therefore systematically sought to explain the residual. Sperman's correlation coefficients indicated that the two most important variables were BMC/BFFFM and SAA, which together explained $29 \%$ of the variance in the residual. Similar to the findings of Koda et al. (26), BMC/BFFFM was negatively associated with the residual of $\% \mathrm{FM}_{\mathrm{ADP}}$ and $\% \mathrm{FM}_{\mathrm{DXA}}$. The negative correlation in the current study may have been due to a violation of the assumption underlying the two-compartment model of body composition, that the density of fat-free mass is $1.100 \mathrm{~g} / \mathrm{cm}^{3}$. A decrease in density of fat-free mass, as would occur with reduced BMC, would lead to an overestimation of fat mass. This may be the case in the current study. By virtue of their young age, our subjects likely had a smaller proportion of fat-free mass as bone and a greater proportion as water (13). The resulting regression equation for $\% \mathrm{FM}_{\mathrm{DXA}}$, which included BMC/BFFFM, reduced both the number of subjects for whom the difference between methods was $>5 \% \mathrm{FM}$ to five, as well as the SEE of the regression. We recommend this equation be tested prospectively in an independent group of African American boys and girls.

SAA was positively correlated with the residual. Because SAA is a negative value, a positive correlation can be interpreted as meaning that as surface area of the subject decreases, the residual between methods increases. This relates to the fact that ADP may be invalid for small subjects. For example, the highest residual between methods $(22.3 \% \mathrm{FM})$ in the current study belonged to the smallest subject, a boy who weighed 25.3 $\mathrm{kg}$ and had a BMI of 13.5 and an SAA of -0.469 . Not surprising, the correlation between $\% \mathrm{FM}_{\mathrm{ADP}-\mathrm{Siri}}$ and $\% \mathrm{FM}_{\mathrm{DXA}}$ was low and nonsignificant in subjects $<35 \mathrm{~kg}$. Similarly, Demerath et al. (21) reported a lower reliability of ADP relative to hydrodensitometry in children versus adults and suggested this may have been due to a system calibration problem for individuals of small volume. They hypothesized that because the volume of the test chamber is constant at 450 $\mathrm{L}$, greater imprecision would be expected for subjects with lower body volumes. We are in agreement with this hypothesis.

Finally, there was a trend toward $\% \mathrm{FM}_{\mathrm{ADP}-\text { Siri }}$ underestimating $\% \mathrm{FM}_{\mathrm{DXA}}$ in girls by $1.5 \%$ but not in boys. This is similar to the findings of Nicholson et al. (19), who reported that $\% \mathrm{FM}_{\mathrm{ADP}-\text { Siri }}$ significantly underestimated $\% \mathrm{FM}_{\mathrm{DXA}}$ in girls by $3.0 \%$. The authors noted that the underestimation may have been caused by girls' wearing a full one-piece bathing suit, as opposed to the briefs or tight-fitting bathing suits worn by boys. The effect of clothing is to artificially decrease body volume by introducing isothermal air into the chamber; this results in artificially increased body density $(1,27)$ and thereby decreased body fat. However, many of the girls in the present study did wear two-piece bathing suits. The reason for the slight underestimation of \%FM by ADP relative to DXA in girls therefore remains to be elucidated.

We found that predicted lung volume is significantly higher than and only modestly associated with measured lung volume in children. As a result, ADP overestimates $\%$ FM relative to that calculated using measured lung volume and relative to DXA. This is concerning as lung volume has been predicted in a number of pediatric studies using ADP (2-4,19-21). Of these studies, Demerath et al. (21) also found predicted lung volume to be higher than $(p<$ $0.05)$ and modestly associated with $\left(R^{2}=0.58\right)$ measured lung volume in 39 children $8-17 \mathrm{y}$. As a result, $\% \mathrm{FM}_{\text {ADP-Siri }}$ was $1.4 \%$ greater $(p<0.05)$ than that using measured lung volume and was significantly greater than $\% \mathrm{FM}$ determined by hydrodensitometry. In their study of 37 children $10-18$ y, Lockner et al. (3) found body density by ADP to be significantly lower using predicted versus measured lung volume. Although not reported, a lower body density must result in a higher \% $\%$ M as body density is in the denominator of all equations used to calculate \%FM. However, Nicholson et al. (19) found no systematic differences in results using predicted lung volume between the 10 children who were unable to give an adequate test and those with measured lung volume only, and Nunez et al. (2) concluded that use of predicted versus measured lung volume was not the source of the observed bias in body density by ADP versus hydrodensitometry in their study of 48 children. 
These discrepant findings seem to be unique to the pediatric population as no differences in predicted versus measured lung volume or in subsequent \%FM estimates were reported in adults $18-69$ y $(21,28)$. This is not surprising and may be caused in part by choice of predictive equations. The equation of Crapo et al. (18), used in the pediatric and adults subjects by Demerath et al. (21) and in the adult subjects by McCrory et al. (28), was validated in adolescents and adults 15-91 y. The manufacturer equation, used in the pediatric studies of Nicholson et al. (19) and Lockner et al. (3), is a proprietary modification of the Crapo et al. equation. However, Wells and Fuller (20) and Dewit et al. (4) used the pediatric equations of Rosenthal/Zapletal. We found even these pediatric equations to overpredict measured lung volume, resulting in an overestimation of \%FM. We considered that presence of sickle cell disease may have contributed to this, as even in steady state, children with sickle cell disease may have reduced total lung capacity, forced vital capacity, and/or forced expiratory volume (29-31). However, there was neither a numeric nor a statistical difference in measured lung volume between control subjects and subjects with sickle cell disease in the current study, and there were no differences in residuals between predicted (using either set of equations) and measured lung volume between these two subgroups. The reason for the poor performance of the pediatric predictive equations remains unknown. Until more appropriate predictive equations are developed, we recommend the use of measured lung volume in pediatric subjects.

Limitations. Our study contributes to some gaps in the literature pertaining to use of ADP in children, but two limitations bear mentioning. First, our small sample size precludes us from fully investigating the residual between ADP-Siri and DXA in subgroups, particularly girls $(n=13)$ and subjects $<35 \mathrm{~kg}(n=10)$. Nonetheless, we are able to extend current knowledge by confirming the preliminary finding that ADP may underestimate $\% \mathrm{FM}$ in girls, as well as confirming the manufacturer's recommendation that ADP be used with caution in subjects $<35 \mathrm{~kg}$. Future studies may further explore the reason for the difference between methods by sex and by weight category.

Second, we did not measure density of fat-free mass of our subjects. Our subjects were young (9 to $14 \mathrm{y}$ old); therefore, density may have been lower than the assumed constant of $1.100 \mathrm{~g} / \mathrm{cm}^{3}$, as a result of lower BMC. However, BMC is higher in African American than white children and adolescents (14-16), so the overall effect on the density of fat-free mass in our subjects is not known. We did, however, find a strong association between BMC per unit of BFFFM and the residual between ADP-Siri and DXA and so were able to confirm indirectly the importance of taking the density of fat-free mass into account when applying a two-compartment model of body composition to pediatric subjects.

\section{CONCLUSIONS}

We conclude that in 9- to 14-y-old African American children and at the group level, body fat calculated from application of the Siri equation to ADP density measurements approximates that obtained by DXA, provided that lung volume is measured, not predicted. Body composition results obtained by ADP in children $<35 \mathrm{~kg}$ should be interpreted with caution.

Acknowledgments. We gratefully acknowledge the volunteers and families for enthusiasm and for participation in the study. We also thank the staff of the General Clinical Research Center at Vanderbilt University Medical Center for help with this project, Daniel Byrne for statistical advice and expertise, and LeMonica Lewis for helping to coordinate the study.

\section{REFERENCES}

1. Dempster P, Aitkens S 1995 A new air displacement method for the determination of human body composition. Med Sci Sports Exerc 27:1692-1697

2. Nunez C, Kovera AJ, Pietrobelli A, Heshka S, Horlick M, Kehayias JJ, Wang Z, Heymsfield SB 1999 Body composition in children and adults by air displacement plethysmography. Eur J Clin Nutr 53:382-387

3. Lockner DW, Heyward VH, Baumgartner RN, Jenkins KA 2000 Comparison of air-displacement plethysmography, hydrodensitometry, and dual X-ray absorptiometry for assessing body composition of children 10 to 18 years of age. Ann N Y Acad Sci $904: 72-78$

4. Dewit O, Fuller NJ, Fewtrell MS, Elia M, Wells JC 2000 Whole body air displacement plethysmography compared with hydrodensitometry for body composition analysis. Arch Dis Child 82:159-164

5. Fields DA, Goran MI 2000 Body composition techniques and the four-compartment model in children. J Appl Physiol 89:613-620

6. Wells JC, Douros I, Fuller NJ, Elia M, Dekker L 2000 Assessment of body volume using three-dimensional photonic scanning. Ann N Y Acad Sci 904:247-254

7. Siri WE 1961 Body composition from fluid spaces and density: analysis of methods In: Techniques for Measuring Body Composition. National Academy of Sciences/ National Research Council, Washington, DC, pp 223-224

8. Schutte JE, Townsend EJ, Hugg J, Shoup RF, Malina RM, Blomqvist CG 1984 Density of lean body mass is greater in blacks than in whites. J Appl Physiol 56:1647-1649

9. Lohman TG, Slaughter MH, Boileau RA, Bunt J, Lussier L 1984 Bone mineral measurements and their relation to body density in children, youth and adults. Hum Biol 56:667-679

10. Wells JC, Fuller NJ, Dewit O, Fewtrell MS, Elia M, Cole TJ 1999 Four-component model of body composition in children: density and hydration of fat-free mass and comparison with simpler models. Am J Clin Nutr 69:904-912

11. Bray GA, DeLany JP, Harsha DW, Volaufova J, Champagne CC 2001 Evaluation of body fat in fatter and leaner 10-y-old African American and white children: the Baton Rouge Children's Study. Am J Clin Nutr 73:687-702

12. Westrate JA, Deurenberg P 1989 Body composition in children: proposal for a method for calculating body fat percentage from total body density or skinfoldthickness measurements. Am J Clin Nutr 50:1104-1115

13. Lohman TG 1986 Applicability of body composition techniques and constants for children and youths. Exerc Sport Sci Rev 14:325-357

14. Horlick M, Thornton J, Wang J, Levine LS, Fedun B, Pierson RN Jr 2000 Bone mineral in prepubertal children: gender and ethnicity. J Bone Miner Res 15:13931397

15. Ellis KJ 1997 Body composition of a young, multiethnic, male population. Am J Clin Nutr 66:1323-1331

16. Nelson DA, Barondess DA 1997 Whole body bone, fat and lean mass in children: comparison of three ethnic groups. Am J Phys Anthropol 103:157-162

17. Dwyer JT, Stone EJ, Yang M, Webber LS, Must A, Feldman HA, Nader PR, Perry CL, Parcel GS 2000 Prevalence of marked overweight and obesity in a multiethnic pediatric population: findings from the Child and Adolescent Trial for Cardiovascular Health (CATCH) study. J Am Diet Assoc 100:1149-1156

18. Crapo RO, Morris AH, Clayton PD, Nixon CR 1982 Lung volumes in healthy nonsmoking adults. Bull Eur Physiopathol Respir 18:419-425

19. Nicholson JC, McDuffie JR, Bonat SH, Russell DL, Boyce KA, McCann S, Michae M, Sebring NG, Reynolds JC, Yanovski JA 2001 Estimation of body fatness by air displacement plethysmography in African American and white children. Pediatr Res 50:467-473

20. Wells JC, Fuller NJ 2001 Precision of measurement and body size in whole-body air-displacement plethysmography. Int J Obes Relat Metab Disord 25:1161-1167

21. Demerath EW, Guo SS, Chumlea WC, Towne B, Roche AF, Siervogel RM 2002 Comparison of percent body fat estimates using air displacement plethysmography and hydrodensitometry in adults and children. Int $\mathrm{J}$ Obes Relat Metab Disord 26:389-397

22. Prior BM, Cureton KJ, Modlesky CM, Evans EM, Sloniger MA, Saunders M, Lewis RD 1997 In vivo validation of whole body composition estimates from dual-energy X-ray absorptiometry. J Appl Physiol 83:623-630

23. Rosenthal M, Cramer D, Bain SH, Denison D, Bush A, Warner JO 1993 Lung function in white children aged 4 to 19 years: II - single breath analysis and plethysmography. Thorax 48:803-808

24. Zapletal A, Paul T, Samanek M 1976 [Normal values of static pulmonary volumes and ventilation in children and adolescents]. Cesk Pediatr 31:532-539

25. Bland JM, Altman DG 1986 Statistical methods for assessing agreement between two methods of clinical measurement. Lancet 1:307-310 
26. Koda M, Ando F, Niino N, Tsuzuku S, Shimokata H 2000 Comparison between the air displacement method and dual energy $\mathrm{x}$-ray absorptiometry for estimation of body fat. J Epidemiol 10:S82-S89

27. Fields DA, Hunter GR, Goran MI 2000 Validation of the BOD POD with hydrostatic weighing: influence of body clothing. Int J Obes Relat Metab Disord 24:200-205

28. McCrory MA, Mole PA, Gomez TD, Dewey KG, Bernauer EM 1998 Body composition by air-displacement plethysmography by using predicted and measured thoracic gas volumes. J Appl Physiol 84:1475-1479
29. Jaja SI, Opesanwo O, Mojiminiyi FB, Kehinde MO 2000 Lung function, haemoglobin and irreversibly sickled cells in sickle cell patients. West Afr J Med 19:225-229

30. Pianosi P, D’Souza SJ, Charge TD, Esseltine DE, Coates AL 1993 Pulmonary function abnormalities in childhood sickle cell disease. J Pediatr 122:366-371

31. Wall MA, Platt OS, Strieder DJ 1979 Lung function in children with sickle cell anemia. Am Rev Respir Dis 120:210-214

32. Fomon SJ, Haschke F, Ziegler EE, Nelson SE 1982 Body composition of reference children from birth to age 10 years. Am J Clin Nutr 35:1169-1175 